\title{
Anti-M-CSF Monoclonal Antibody MCS110
}

National Cancer Institute

\section{Source}

National Cancer Institute. Anti-M-CSFMonoclonal Antibody MCS110. NCI Thesaurus. Code C80044.

A humanized monoclonal antibody directed against macrophage colony-stimulating factor (M-CSF) with potential anti-osteolytic activity. Anti-M-CSF monoclonal antibody MCS110 binds to M-CSF and blocks M-CSF-mediated signaling through the M-CSF receptor CD116 expressed on osteoclasts, which may result in inhibition of M-CSFinduced osteoclast differentiation and so osteoclastic bone resorption. Osteoclasts are derived through the fusion of cells of the monocyte/macrophage lineage. Osteoblasts and stromal cells may react to bone metastases by producing M-CSF and its osteoclastogenic cofactor RANKL (receptor activator of NF-kappaB ligand). 